\title{
A PUBLICIDADE E A CONSTRUÇ̃̃O DA MASCULINIDADE: AS REPRESENTAÇÕES DE GÊNERO EM MALVINO SALVADOR
}

\author{
THE ADVERTISING AND THE MALE PERFORMANCE: GENDER REPRESENTATION IN MALVINO SALVADOR
}

\section{RESUMO}

O presente artigo propõe analisar duas produções publicitárias audiovisuais com o objetivo de estudar a construção da masculinidade (ou masculinidades) nesse conteúdo como forma de representação. O corpus é constituído pelas peças "O chamado", da marca Old Spice, e "Festinha", das Havaianas, ambas protagonizadas pelo ator Malvino Salvador. A partir da Análise de Conteúdo, como método empírico, e sob a ótica da teórica Badinter (1993), aliada aos Estudos Culturais, pretende-se entender como se concretiza a representação de modelos de masculinidade a partir de padrões que se contrapõem na narrativa dos anúncios e como a publicidade influencia na formação das identidades, fragmentadas em tempos contemporâneos. Como resultado, observamos diferentes formas de "ser homem" coexistirem numa mesma época e que a celebração da virilidade em uma perspectiva machista ainda é um modelo de representação em voga, mesmo frente a questionamentos por parte da sociedade.

Palavras-chave: Publicidade. Masculinidade. Identidade. Análise de Conteúdo.

\begin{abstract}
This article proposes to analyze two audiovisual advertising productions aiming to study the male performances in the present content as representativeness. The ads "O chamado", from the brand Old Spice, and "Festinha", from Havaianas, both starred by the actor Malvino Salvador. Through Content Analysis, as an empiric method, and the perspective of the theoretical Badinter (1993), together with Cultural Studies, it is intended to understand how the male representativeness is performed based on patterns which are opposed in the narratives of the productions and how advertising influences the identity formation, which are fragmented in contemporaneity. As a result, we have observed different forms of "being a man" to coexist in the same social period and that the celebration of virility, in a male chauvinist perspective, is still there, although the society questions it.
\end{abstract}

Keywords: Advertising. Masculinity. Identity. Content Analysis.

Renata B. Malta

Universidade Federal de Sergipe (UFS). E-mail: renatamaltarm@gmail.com

Wesley S. Andrade

Universidade Federal de Sergipe (UFS). E-mail: loothlorien@gmail.com

Gabriel S. Cordeiro

Universidade Federal de Sergipe (UFS). E-mail: gabrielscordeiro75@gmail.com

Lilian R. S. S. Alves

Universidade Federal de Sergipe (UFS). E-mail: lilianraquel49@gmail.com 


\section{Introdução}

Sob a perspectiva dos Estudos Culturais, a identidade possui um caráter inacabado e está em constante construção. A partir desse pressuposto, para embasar esta pesquisa, nossa fundamentação teórica se alicerça principalmente nos culturalistas Hall (2011), Williams (1980) e Woodward (2011). Para uma discussão mais aprofundada acerca dos modelos de masculinidade e suas formas de representação social, contamos com a contribuição dos estudos teóricos de Badinter (1993), a qual afirma que a identidade masculina na pós-modernidade exige constante reafirmação e vive em conflito.

Ao nos deslocarmos para o sendeiro do empírico, propomos analisar um corpus constituído por duas peças publicitárias, a campanha "Festinha" (2016), da marca de sandálias "Havaianas", e a campanha "O Chamado" (2013), da marca de desodorantes masculinos "Old Spice". Ambas as peças foram protagonizadas pelo mesmo ator, Malvino Salvador, e abordam diferentes representações acerca de modelos de masculinidade. Para tanto, definimos como método a Análise de Conteúdo proposta por Bardin (2006). A autora afirma quealém de medir a frequência de um determinado conteúdo, o que não se aplicaria ao nosso objeto, o método também permite que categorizemos esse conteúdo. Assim, buscaremos observar características do conteúdo descrito em elementos variáveis - em temáticas ou categorias - previamente e sistematicamente codificadas, as quais expressem os diferentes modelos de representação de masculinidades presente no corpus, também de forma comparativa. Nesse sentido, pretende-se elucidar como as duas marcas fizeram uso da imagem do mesmo ator para comunicar conceitos distintos acerca da identidade masculina, ainda que congruências se façam presentes, além de proporcionar prestígio à marca e dar credibilidade à mensagem.

\section{Identidades pós-modernas}

A partir dos Estudos Culturais, um novo conceito de identidade é construído na sociedade moderna, ao se questionar o caráter fixo da identidade e como se dá seu reconhecimento social. Nesse âmbito, Hall (2011, p. 89) define identidade como um "significado cultural e socialmente atribuído". Sendo assim, ela é sempre inacabada, está em constante renovação e construção através dos discursos, como também da relação sociocultural entre os indivíduos. De acordo com Silva (2011), a identidade é marcada pela diferença à medida queestabelece distinções frequentemente na forma de oposições binárias. De acordo com o autor, esta diferença pode ser construída de forma negativa e levar à exclusão ou à marginalização dos que são considerados os “outros", como também pode ser celebrada como fonte de diversidade e enriquecimento. Nessa perspectiva, há uma hierarquização das identidades, uma vez queaquelas consideradas hegemônicas impõem-se discursiva e ideologicamente sobre as que não são. Para 
Silva (2011, p. 96), "a identidade é instável, contraditória, fragmentada, inconsistente, inacabada. A identidade está ligada a estruturas discursivas e narrativas. A identidade está ligada a sistemas de representação. A identidade tem estreitas conexões com relações de poder".

Decorrente da chegada da globalização e das transformações que acompanham a sociedade líquido-moderna, as identidades tornam-se mais instáveis e voláteis, "algumas por escolha própria, outras lançadas por outras pessoas e entidades", como afirma Bauman (2005, p. 25). Nesse sentido, as identidades contemporâneas, tendo em vista a sua liquidez, são frágeis e provisórias e vivem em meio a crises e incertezas decorrentes da nova dinâmica social estabelecida. Ademais, Bauman (2005, p. 35) afirma que "as identidades ganharam livre curso, e agora cada indivíduo, homem ou mulher, pode capturá-las em pleno voo, usando os seus próprios recursos e ferramentas".

Outro acontecimento que influenciou diretamente o reconhecimento identitário na pós-modernidade foi o capitalismo. Diante do caráter fluido e a liquidez das relações sociais, a sociedade de consumo, num contexto pós-guerra, foi também analisada por Bauman (2001, p.98). Segundo o autor, "compartilhar a dependência de consumidor - a dependência universal das compras - éa condição 'sine qua non’ de toda liberdade individual; acima de tudo, da liberdade de ser diferente, de ter identidade". Nesse contexto, as pessoas líquido-modernas encontraram no consumo não apenas uma suposta forma de realizar desejos e satisfazer prazeres, mas uma possibilidade de consumar a busca pela sua identidade frágil e inatingível. Nesse contexto, somos antes de mais nada interpelados como consumidores.

É no ambiente de consumo que observar as narrativas midiáticas como produções culturais que influenciam na construção identitária dos indivíduos passa a fazer sentido, sobretudo da publicidade. Woodward (2011, p.33) relata que "existe uma associação entre a identidade da pessoa e as coisas que ela usa”. Mais além, para a autora,

A mídia nos diz como devemos ocupar uma posição-de-sujeito particular - o adolescente "esperto", o trabalhador em ascensão, ou a mãe sensível. Os anúncios só serão "eficazes" no seu objetivo de nos vender coisas se tiverem apelo para os consumidores e se fornecerem imagens com as quais eles possam se identificar. (WOODWARD, 2011, p. 18)

Isso significa que os indivíduos são constantemente interpelados pela mídia a assumirem posições de sujeito. Kellner (2001) também reforça a ideia de que a cultura da mídia - através de suas produções literárias, cinematográficas, televisivas e publicitárias - projetam identidades culturais e, especialmente hegemônicas, a serem seguidas.

Com a largada capitalista e os desdobramentos sociais pós Primeira Guerra Mundial, a publicidade expandiu-se e ganhou espaço entre as formas de comunicação. 
Este "sistema mágico" foi estudado e definido por Williams (1980, p. 253) como um "sistema altamente organizado e profissional de persuasão e satisfação". Segundo o autor (1980), se estivéssemos em uma sociedade materialista, a publicidade continuaria centrada apenas em anunciar um produto, pois estaríamos interessados somente no objeto. Contudo, Williams (1980, p. 252) afirma que "é impossível olharmos para a publicidade sem percebermos que o objeto material à venda nunca se basta", portanto, pressupõe-se que os valores simbólicos e pessoais associados ao produto são cruciais para despertar o nosso interesse. Nesse sentido, o autor (1980, p. 252) exemplifica que "a cerveja nos bastaria, sem a promessa adicional de que, tomando-a, pareceríamos mais viris, mais jovens ou mais sociáveis".

Portanto, a publicidade é uma importante produtora de sistemas simbólicos no âmbito cultural, além de delimitar as diferenças individuais. Ela apropria-se de valores sociais e faz uso da persuasão para vender produtos ou bens materiais que ganham sentido por meio do consumo.

\section{Identidade em crise: a (des) construção da masculinidade}

A evolução e a completude do tornar-se masculino foi uma questão estudada por Badinter (1993) em sua obra sobre a construção da identidade masculina. A autora disserta sobre o que é ser homem pós século XX e faz uma associação da masculinidade à virilidade. Além disso, ela acrescenta que muitos argumentam a respeito do "verdadeiro homem" ocidental, o qual teve sua identidade masculina abalada com o impacto que o feminismo dos anos 6o e 70 trouxe à sociedade. Segundo Badinter (1993, p. 6), "as mulheres fizeram evaporar-se a característica universal masculina: a superioridade do homem sobre a mulher". A autora (1993, p. 10) explica que o homem não é mais o "Homem" e contextualiza essa afirmação ao mencionar que "o macho é um aspecto da humanidade e a masculinidade um conceito relacional, pois só é definida com relação à feminilidade". Essa ideia serve como reflexão, uma vez que os papeis de gênero, raça e sexualidade na sociedade só existem em contraponto ao outro. Assim, Badinter (1993, p. 10) também associa que nesse contexto dicotômico "a mulher é o outro, estrangeiro e incompreensível".

De forma resumida, a autora (1993, p. 10) disserta que a construção social da masculinidade, ou masculinidades, é mutável no decorrer dos séculos. Sendo assim, ela assinala que alguns homens da sociedade Francesa e Inglesa do século XVII e XVIII fugiam do estereótipo do homem bruto e exigente, os quais eram denominados de "preciosos", além disso, Badinter (1993, p. 13) também pontua que "os homens que queriam distinguir-se faziam questão de parecer civilizados, corteses e delicados", adotavam uma moda refinada, com o uso de perucas longas, plumas, roupas com abas, maquiagem e perfumes. Assim, o retrato do "homem efeminado" com um alto grau de complacência e compaixão foi um comportamento comum no homem francês e inglês daquela época, contudo, suscitava um temor da homossexualidade. A autora 
comenta que os homens destes séculos não se interessavam mais pela caça ou guerra, o importante era o tempo gasto em salões ou nos aposentos das mulheres, a delicadeza e as atitudes minimalistas simbolizavam a virilidade.

Badinter (1993) explica que a crise da masculinidade começa na virada dos séculos XIX e XX, quando as mulheres reafirmam seu papel na sociedade ao exigir direitos e igualdade de gênero, o que desencadeou um comportamento hostil dos homens em suas variadas posições:políticas, religiosas e o próprio movimento operário, visto que receberam com repúdio toda essa organização em relação à emancipação feminina. A autora (1993) argumenta que o maior dos temores dos homens é a ameaça iminente aos seus poderes, sua identidade e sua vida cotidiana, ou seja, a ameaça aos privilégios inerentes ao gênero. Além disso, Badinter (1993) pontua que diante da crise da masculinidade pós século XIX, houve uma associação de mulher emancipada com mulher masculinizada, como se a atitude passiva e afável fosse uma característica de natureza feminina e o fato do indivíduo ser ativo ou de tomar posicionamentos que possam ferir o privilégio masculino a tornava um "homem num corpo feminino, uma virago" (p. 17).

A autora (1993) contextualiza que o conceito de bissexualidade, introduzido por Freud e retomado por Weininger, faz com que o "lado feminino" de cada um se torne irredutível e provoca a reflexão de que a virilidade nunca está adquirida de forma perpétua, ainda que essa associação entre orientação sexual e identidade de gênero se dê por conta de uma linearidade errônea. No fim do século XIX houve a publicação massiva de obras difamatórias para explicar que o sexo feminino era inferior ao masculino, principalmente com apelo à biologia. Segundo Badinter (1993), estas obras afirmavam que as mulheres eram mais próximas dos animais e dos negros, com alma infantil, dominada por instintos primitivos e maternais, os quais lhes designavam sua única vocação - ser mãe.

Badinter (1993) também defende que a mudança para o sistema capitalista pósguerra foi outro fator crucial para gerar a crise da masculinidade. A vida familiar e os seus valores foram intensamente modificados, os homens foram forçados a trabalhar longe dos lares e longe dos filhos, fazendo com que essa responsabilidade, no contexto familiar, recaísse sobre as mulheres. A autora (1993, p. 20-21) explica que a paternidade tornou-se uma "instituição dominical" e a virilidade agora estava associada ao sucesso profissional. Ademais, ela afirma que havia um temor da sociedade em relação à criação dos meninos - criar os filhos era um dos papeis sociais impostos à mulher para não criá-los com muitos mimos, pois assim as mães poderiam "sabotar a virilidade dos filhos". A virilidade masculina moderna foi reescrita, o que antes era associado a perucas, maquiagens e adornos hoje é associada à violência, à força, ao combate e à dominação do homem sobre a mulher.

O pensamento de Badinter (1993) sobre masculinidades e as contribuições de autores que discorrem acerca da pós-modernidade e da cultura como eixo social, determinante de relações de poder que abarcam, além da classe, gênero, raça e sexualidade, são aqui não apensas fundamentação teórica basilar, mas também nos servirão de alicerce para a pesquisa empírica que proporemos a seguir. 


\title{
Pesquisa empírica
}

Para a elaboração desta etapa da pesquisa, optamos pela Análise de Conteúdo qualitativa, não com a finalidade de conhecer a frequência, mas sim as características do conteúdo do corpus, categorizando-o a partir de critérios pré-definidos. De acordo com Bardin (2006), a Análise de Conteúdo é caracterizada por uma gama de instrumentos metodológicos que se aplicam a discursos variados. Nesse âmbito, Moraes (1999) especifica que a Análise de Conteúdo é uma análise de dados qualitativos e quantitativos, um método usado para interpretar dados em textos ou imagens. $\mathrm{O}$ autor esclarece que essa metodologia é muito mais que uma simples análise de dados.

\begin{abstract}
A Análise de Conteúdo constitui uma metodologia de pesquisa usada para descrever e interpretar o conteúdo de toda classe de documentos e textos. Essa análise, conduzindo a descrições sistemáticas, qualitativas ou quantitativas, ajuda a reinterpretar as mensagens e a atingir uma compreensão de seus significados num nível que vai além de uma leitura comum. (MORAES, 1999, p.o2)
\end{abstract}

Pontuamos que o modo de categorização estipulada do corpus foi baseado na tese de doutorado proposta por Malta (2013), onde a autora sistematiza, com o uso da Análise de Conteúdo, como ocorre o jogo das representações dentro de comerciais automobilísticos no decorrer das décadas. Segundo Bardin (2006), para que a análise seja válida, essas categorias precisam ser: homogêneas, exaustivas, exclusivas, objetivas e pertinentes. Dessa forma, Moraes (1999) explica as categorias propostas por Bardin (2006): o conceito de homogeneidade explana que a organização deve ser fundamentada em um único princípio ou critério de avaliação; o conceito de exaustão deve-se extrair tudo que o texto é passível de oferecer e possibilitar a categorização de todo conteúdo significativo, definido em convergência com os objetivos da análise; o conceito de exclusividade se aplica ao dizer que cada elemento possa ser codificado apenas em uma categoria; o de objetividade quando o texto categorizado possa e deva possibilitar clareza no seu propósito final e o de pertinência quando explica que as categorias criadas no decorrer do texto sejam úteis, significativas e dialoguem a todo momento com o objetivo proposto.

Para as análises, definimos como corpus dois vídeos publicitários intitulados "Festinha" (2016), da marca de sandálias "Havaianas", e "O Chamado" (2013), da marca de desodorantes masculinos "Old Spice”. Ambas as peças foram protagonizadas pelo mesmo ator, Malvino Salvador, e expressam diferentes representações acerca de modelos de masculinidade. Nosso objetivo, assim, é elucidar quais são os modelos de representação ali presentes e como as duas marcas fizeram uso da imagem do mesmo ator para comunicar conceitos distintos acerca da identidade masculina, ainda que congruências se façam presentes. 
Quadro 1: Categorização das representações de identidades masculinas na figura do ator Malvino Salvador identificadas no corpus, com breve descrição.

\begin{tabular}{|c|c|l|}
\hline Peça & $\begin{array}{c}\text { Representação da } \\
\text { masculinidade }\end{array}$ & \multicolumn{1}{c|}{ Detalhamento } \\
\hline \multirow{7}{*}{$\begin{array}{c}\text { Havaianas } \\
\text { Festinha }\end{array}$} & $\begin{array}{c}\text { Homem com amigos } \\
\text { na mesa de bar }\end{array}$ & $\begin{array}{l}\text { Três homens, sendo um deles o Malvino Salvador, conversam } \\
\text { e bebem cerveja na mesa de um bar sobre uma possível festa; } \\
\text { Ao fundo, dois homens coadjuvantes em mesas separadas. }\end{array}$ \\
\cline { 2 - 4 } & $\begin{array}{c}\text { Barba como } \\
\text { "cosmético" } \\
\text { masculino }\end{array}$ & $\begin{array}{l}\text { Os dois amigos do Malvino Salvador ostentam a barba com } \\
\text { mais volume, esteticamente definida, enquanto Malvino } \\
\text { está com a barba por fazer, com coloração cinza e fio curto. }\end{array}$ \\
\cline { 2 - 4 } & \begin{tabular}{c} 
vomaidoso \\
\cline { 2 - 4 }
\end{tabular} & $\begin{array}{l}\text { Malvino Salvador narra com detalhes com que indumentária } \\
\text { irá à festa, dando foco ao tipo de calçado que vestirá, sendo } \\
\text { esse calçado as Alpargatas das Havaianas. }\end{array}$ \\
\cline { 2 - 4 } & $\begin{array}{l}\text { Homem irônico, } \\
\text { pergunta dúbia que é, Malvino relaciona a questão com } \\
\text { as vestimentas e responde categoricamente como irá; A } \\
\text { resposta é recebida com estranheza, chacota e ironia; } \\
\text { Os mesmos amigos que o acompanham o tem como bobo } \\
\text { quando ele responde confusamente ao questionamento da } \\
\text { mulher. }\end{array}$ \\
\cline { 2 - 4 } & Homem carinhoso & $\begin{array}{l}\text { Malvino Salvador recebe a antiga colega de classe com um } \\
\text { abraço apertado e com o tom de voz suave. }\end{array}$ \\
\hline
\end{tabular}

\begin{tabular}{|c|c|c|}
\hline Peça & $\begin{array}{c}\text { Representação da } \\
\text { masculinidade }\end{array}$ & Detalhamento \\
\hline \multirow{5}{*}{$\begin{array}{l}\text { Old Spice } \\
\text { O chamado }\end{array}$} & $\begin{array}{l}\text { Homem musculo- } \\
\text { so, barbudo e sem } \\
\text { camisa }\end{array}$ & $\begin{array}{l}\text { Homem ilhado, forte, barbudo; } \\
\text { Estátua fixa que ganha movimento; } \\
\text { Boxeador com vestimentas do esporte e corpo tatuado. }\end{array}$ \\
\hline & Bem sucedido & $\begin{array}{l}\text { Homem branco, galanteador, elegante e cavalheiro. Dono } \\
\text { de um carro esportivo de alto valor aquisitivo e aclamado } \\
\text { pelos fotógrafos; } \\
\text { Malvino Salvador é detentor de um apartamento bem deco- } \\
\text { rado e ao fundo mostra a sua moto. }\end{array}$ \\
\hline & $\begin{array}{l}\text { Homem romântico e } \\
\text { galante }\end{array}$ & $\begin{array}{l}\text { Homem branco, bem vestido que protege as suas duas } \\
\text { acompanhantes de serem molhadas pela lama com o seu } \\
\text { terno, como se o mesmo servisse como escudo; } \\
\text { Malvino Salvador, que após acender as velas, dá um beijo } \\
\text { em sua acompanhante. }\end{array}$ \\
\hline & Homem aventureiro & $\begin{array}{l}\text { O homem ilhado que decide ir andando por dentro da água. } \\
\text { O mesmo respira por um buraco feito em um coco; } \\
\text { Malvino Salvador acende as velas com um lança chamas e } \\
\text { posteriormente estaciona a moto de uma maneira inusi- } \\
\text { tada, sendo projetada contra uma parede e causando uma } \\
\text { explosão; } \\
\text { Bombeiro que, com a roupa em chamas, se aventura a ir ao } \\
\text { chamado do Old Spice sem apagar o fogo em sua vestimen- } \\
\text { ta; } \\
\text { Homens que correm sem parar em direção do chamado do } \\
\text { Old Spice. }\end{array}$ \\
\hline & Homem "Homem" & $\begin{array}{l}\text { A locução masculina em voice over - voz em off - repre- } \\
\text { senta uma voz divina que tem o poder de convocar para "o } \\
\text { chamado" todos os homens "machos" da narrativa. }\end{array}$ \\
\hline
\end{tabular}




\section{Interpretação dos resultados}

Primeiramente, para análise do corpus, foram criadas categorias para definir e sistematizar como os modelos de masculinidade são retratados nas peças de acordo com seus elementos estilísticos e narrativos. Antes de pontuarmos a interpretação das informações obtidas, é fundamental perceber o uso da imagem do ator Malvino Salvador e a contribuição da Escola Funcionalista ao discorrer sobre credibilidade da fonte e a associação das celebridades à publicidade. Nesse sentido, Melton e Lazarsfeld (1990) argumentam sobre a função de atribuição de status, muito usada pela propaganda, em que "pessoas da mídia" endossam um produto específico, para destacar e adquirir prestígio para si mesmas e garantir credibilidade ao mesmo. Assim, Melton e Lazarsfeld (1990 p. 116) afirmam que "se você é importante, estará no foco de atenção da massa, e se você está no foco de atenção da massa, então com certeza você é realmente importante". O papel da credibilidade da fonte é essencial, visto que, segundo os autores, a depender da fonte que emita a mensagem, pode-se criar uma mudança de opinião nos consumidores.

Foram observadas nas peças publicitárias diferentes abordagens de masculinidades em seu caráter mutável e socialmente estruturado. Segundo Badinter (1993), tornar-se homem representa uma tarefa a ser cumprida, uma obrigação, e a virilidade como algo a ser construído. A partir desse pressuposto, entende-se que a virilidade se constitui de forma dual dentro das campanhas, à medida que em uma reforça os estereótipos de homem como viril, forte, selvagem, rude e conquistador e na outra é retratado um homem mais detalhista, vaidoso, simpático e carinhoso. Duas representações distintas dentro da ideia de masculinidade e curiosamente tendo o mesmo ator, Malvino Salvador, como ícone de representações tão díspares. O ator, que antes trabalhava como modelo fotográfico, despontou na televisão em 2004 e se manteve como personagem de destaque ou protagonista em várias produções globais, na maioria das vezes atuando como "galã". Na vida pessoal, teve várias namoradas e, pelo que consta, nunca se casou. Ainda que não tenhamos a intenção de uma análise da biografia do ator, entendemos que a imagem de galã e de namorador, tendo a heterossexualidade afirmada na vida real e na ficção, são importantes para a construção dos personagens ficcionais das peças publicitárias analisadas.

A formação de identidade, segundo Woodward (2011), é relacional, se dá pelo apelo a referências, tanto de identidades hegemônicas - o consumidor soberano, o cidadão patriótico - quanto pela resistência das identidades marginalizadas ou tidas como as "outras". Como discorrido, a partir do capitalismo e da reconfiguração das relações sociais com a pós-modernidade, novos movimentos sociais contrahegemônicos afloram e deixam em crise as próprias identidades, sobretudo o conceito de masculinidade, ou masculinidades, de uma época. Ao relacionar com o tema em questão, os comerciais expõem dois significados diferentes de masculinidade. Nesse âmbito, como prova da mutação destes conceitos e associadas a uma figura pública aclamada, tentam aproximar e familiarizar os consumidores com o produto. Portanto, 
comerciais como estes revelam a responsabilidade da publicidade como mediadora na construção simbólica de conceitos ligados à identidade masculina pós-moderna.

\section{Old Spice "O Chamado" (2013)}

O comercial da Old Spice ${ }^{1}$ apresenta um conceito de masculinidade exagerado e estereotipado, que beira o cômico, alicerçado em um modelo hegemônico de "ser homem”. O vídeo começa ao retratar um homem ilhado - com pele bronzeada, barba com volume, corpo depilado, músculos talhados e bem definidos - na tentativa de retirar o fruto de um coqueiro. $\mathrm{O}$ ator observa o fruto e ao fundo tem-se um tom de cor alaranjado, de acordo com Farina et al. (2011), a cor laranja representa tentação, prazer e energia, o que corrobora com a cena ao mostrar o ator com seu porte atlético e bronzeado. Ao invés de usar meios tradicionais para conseguir retirar a fruta do alto, o mesmo opta por correr em direção à árvore e a atingi-la com um chute preciso, em um plano detalhe que ressalta seus pés e piruetas dignas de espetáculos circenses. A sonoplastia de suspense, com seus efeitos sonoros, indica que o chute tornou-se mais eficiente do que escalar a árvore e tentar retirar o fruto. O coco é derrubado e cai convenientemente em suas mãos, logo em seguida, ele o abre com um golpe de artes marciais, como se as suas mãos fossem tão afiadas quanto uma faca - a sonoplastia contribui com seus efeitos especiais. Entende-se que o estereótipo de aventureiro dialoga com o de virilidade, já que este possui corpo atlético e está inserido em um ambiente natural que exige dele desempenho físico. Suas habilidades são colocadas à prova em encenações que exploram o corpo. Trata-se de aventura como façanha, ousadia ou proeza $^{2}$, sempre expressa positivamente, trazendo à tona sensações de prazer e jamais de incidentes ou perigos reais que coloquem a vida ou a saúde dos personagens em risco. O aventureiro, como expresso no corpus, é aquele atraído por novas experiências, que não se satisfaz com o cotidiano monótono e busca outros desafios em ambientes naturais, já que vencer os obstáculos da natureza se mostra um feito célebre para ele e prova de sua hombridade.

Numa segunda cena é exibido um homem branco saindo de um carro esportivo de alto valor econômico, bem-sucedido, bem vestido, acompanhado por duas mulheres elegantes e aclamado por fotógrafos que o esperam do lado de fora. Ele está de chegada em uma premiação e, ao descer do carro com duas acompanhantes, é surpreendido por um veículo que passa por entre uma poça de lama, projetando-a nas mulheres. $\mathrm{O}$ homem, como um ato de cavalheirismo e heroísmo, usa seu terno como um escudo para evitar que as "damas" fossem molhadas pela lama. Nessa cena, a masculinidade é associada ao fato do homem possuir alto poder aquisitivo, ser cavalheiro, e ser visto acompanhado por duas mulheres. O modelo de homem bemsucedido é reforçado com a ideia da mulher subserviente, já que o personagem é o

1 https://www.youtube.com/watch?v=t8MxQRıbVYc

2 Definições consultadas em Dicionário Eletrônico Houaiss da Língua Portuguesa. 
detentor de bens e dinheiro, uma vez que as mulheres só estão ali como adereço para atestar seu cavalheirismo e a sua masculinidade, mais uma vez associada à virilidade, fama, e poder aquisitivo.

Na terceira cena tem-se a inserção do ator Malvino Salvador, na cozinha de um apartamento, em um jantar à luz de velas, com sua acompanhante. O mesmo prefere acender a vela com um lança chamas e, ao usá-lo, causa uma impressão de sensualidade evirilidade, já que o fogo em exagero simbolizaria a sexualidade aflorada. Logo em seguida, a mulher fica encantada com o feito e o beija. A masculinidade está associada ao poder que o homem tem e a dominação é reforçada ao inserir uma mulher passiva que se encanta com o personagem - que se mistura à figura real do ator que o representa - ao fazer uso de uma arma bélica para acender uma simples vela. Nessa cena, a presença da arma, aparentemente potente, vai muito além de um objeto para composição do cenário, ela pode fazer uma alusão à potência sexual masculina dado pelo modo que Malvino Salvador a manuseia. "O falo é o significante maior, o significante dos significantes, que rege todos os demais (...)” (BADINTER, 1993, p.140).

Podemos trazer aqui as contribuições de Kellner (2001) ao analisar a cultura da mídia a partir de filmes hollywoodianos e outras produções hegemônicas. A representação desta cena tem grande semelhança àquela analisada pelo autor no filme Rambo, associando o personagem à potência bélica, ainda que a maior parte do tempo lute com uma faca - também importante símbolo fálico -, à virilidade eà masculinidade sob a perspectiva hegemônica que provocaria o desejo das mulheres e a inveja dos homens. Ele se mostra preocupante quando afirma que “(...) são as representações que ajudam a construir a visão de mundo do indivíduo, o senso de identidade e sexo, consumando estilos e modos de vida, bem como pensamentos e ações sociopolíticas." (KELLNER, 2001, p.82).

Voltando às análises, ao fundo da cena é inserido um modelo de motocicleta moderna e cara que remete às motos "Harley Davidson", as quais foram historicamente produzidas e comercializadas para o exército Norte Americano durante a I e II Guerra Mundial e tem sua imagem associada ao homem aventureiro, que gosta de explorar novos ambientes com seu modelo de moto customizado e exclusivo.

Na quarta cena, o "chamado" é ouvido e todos os homens seguem em direção ao mesmo. Malvino Salvador, em sua moto, vestido com uma jaqueta marrom, óculos escuros e capacete sem viseira segue em direção a esse chamado. Na chegada do ponto de encontro dos homens, ao invés de estacionar sua moto, ele a arremessa contra a parede e causa uma explosão. Sem ferimentos e de forma heroica, ele segue em direção ao chamado do Old Spice. Nesse sentido, a adrenalina e o efeito cinematográfico dignos de filmes Hollywoodianos são elementos para a composição do conceito de masculinidade retratado e a euforia projetada na cena é reforçada pela sonoplastia.

É importante mencionar, aqui, o significado da voz em locução em off - voice over - que acompanha toda a narrativa. Trata-se de uma voz masculina que representa divindade. Ela descreve o Homem "Homem" como uma espécie em extinção que atrai as mulheres, sexualmente viril, aventureiro, que possui um odor másculo, responsável pelo futuro da humanidade. A trilha sonora e efeitos sonoros possuem 
grande importância para materializar cada performance, assim como simbolizar acusticamente "o chamado" divino.

Na conclusão do vídeo tem-se o encontro de todos dos homens na baía à espera do navio Old Spice. A relação entre a voz "divina" e o barco remete à história da Arca de Noé que, de acordo com o livro Gênesis, começa com Deus observando o mau comportamento da Humanidade e decidindo inundar a Terra. Noé seria o escolhido para dar continuidade à espécie humana. A alusão a esta história bíblica tem um fundo moral e eleva o modelo de masculinidade viril como o "escolhido", aquele capaz de dar continuidade à espécie humana. Ainda que não haja um discurso explícito de preconceito e exclusão, está implícito que todas as outras formas de "ser homem" estariam em desacordo com a divindade, um discurso extremamente problemático e baseado em um modelo hegemônico da masculinidade, aquela explicada por Badinter (1993) como constituída de negativas. Nas palavras da autora:

Tradicionalmente a masculinidade se define mais "por evitar alguma coisa (...) do que por desejar alguma coisa”. Ser homem significa não ser feminino; não ser homossexual, não ser dócil, dependente ou submisso, não ser afeminado na aparência física ou nos gestos; não ter relações sexuais nem relações muito íntimas com outros homens; não ser impotente com as mulheres. (BADINTER, 1993, p.117)

O enquadramento, em plano fechado, dá foco a um bombeiro com a roupa em chamas e as mesmas parecem não o machucar, como se a masculinidade fosse um atributo sobre-humano de proteção que impedisse os homens de sofrer ou ter qualquer injúria física. O representante do Old Spice direciona-se a eles, usando um navio de velas vermelhas. Esta cor foi analisada por Farina et al. (2011) como associada à guerra, mulheres, fogo, perigo, força, energia, agressividade, violência e coragem. Ao chegar, ele narra um pequeno discurso e arremessa o desodorante à multidão; logo após, Malvino captura o objeto e o projeta para cima, como se fosse um troféu. Posteriormente, todos os homens comemoram e o comercial é encerrado.

\section{Havaianas "Festinha" (2016)}

O comercial das sandálias Havaianas "Festinha"3 inicia com dois amigos sentados à mesa de um bar e, com a chegada de uma terceira pessoa, a conversa direciona-se a respeito de uma possível festa que ocorrerá no dia seguinte. Esse terceiro ator veste uma camisa social de cor rosa - a qual socialmente é atribuída ao universo feminino - e possui cabelos mais compridos, na altura do ombro - visto que cabelo longo é outra característica associada às mulheres como marca de feminilidade em uma sociedade binária. Em contrapartida, posicionado à frente dele, está outro ator vestido com uma camiseta de

3 https://www.youtube.com/watch?v=iadO6mc9c8s 
cor azul e com o corte de cabelo mais curto, o qual simboliza uma construção social do universo masculino, a partir de uma lógica hegemônica. Em paralelo, ao centro, está Malvino Salvador, com vestes brancas e cinza, em uma alusão ao neutro.

Malvino, quando questionado como irá a uma festa, entende o questionamento no sentido de como se vestirá para atender ao evento. Em consequência da pergunta, ele responde de forma detalhista o que ele irá calçar (dando foco às Alpargatas das Havaianas), as vestimentas que usará, com uma voz suave e usando adjetivos no diminutivo, o que dá a impressão de um discurso intimista, vaidoso e carismático. Os amigos recebem com estranheza a sua fala, uma vez que a construção social e visual da masculinidade hegemônica dita que o homem precisa ser desleixado e a preocupação com adereços não condiz com o estereótipo masculino. A vaidade, nesse contexto, passa a ser um elemento estético do homem associado à sexualidade, visto que os cuidados com a aparência se tornam um elemento chave no jogo de sedução. Nesse sentido, a barba, referida como um adereço masculino, também se mostra como outro fator crucial para a identidade do homem, sendo utilizada de formas distintas pelos três atores em cena, mas presente em todos eles. A importância dos "adereços" que compõem a "cara" masculina são exaltados por DaMatta (2010). "Realmente, no vocabulário naquela cultura, as mulheres tinham "face”, "seios”, "rosto"; os homens, "peito" e "cara”. Na cara - que era uma região constituída de cabelo, barba e bigode estava a máscara da firmeza e da vergonha, que anunciava o "homem" dentro de cada um de nós” (DAMATTA, 2010, p.139). Entendemos que este elemento, assim como o imaginário coletivo construído em torno do ator ao longo de sua carreira, sempre associadoà heterossexualidadeeà virilidade, afiançariam sua masculinidade, propondo que a preocupação com o cuidado pessoal e, principalmente, o uso de alpargatas da marca também pertencem ao universo masculino. Desse modo, entendemos que a escolha do mesmo ator, que por três anos antes protagonizou a campanha da marca Old Spice, anteriormente analisada, não foi aleatória.

Na sequência, Malvino pergunta aos amigos como eles comparecerão à festa e o ator de camiseta azul responde de forma debochada e firme que iria "de taxi", representando a indelicadeza masculina estereotipada. O protagonista, então, percebe que se confundiu em relação à intencionalidade da pergunta e seus amigos debocham da situação. Posteriormente, uma amiga que não o encontrava há muito tempo o reconhece e o abraça e Malvino a trata gentilmente, com doçura na voz enquanto se cumprimentam. Com o decorrer da conversa entre os dois, a piada anteriormente citada volta à tona com um novo sentido, o que causa descontração no ambiente e resume o humor que gira em torno da cena no modo geral, em seguida, o comercial é encerrado.

O conceito de masculinidade no vídeo também é reforçado ao inserir uma mulher de corpo esbelto - adequado aos padrões de beleza aculturados como ideal - e com um vestido ajustado, a qual entra em cena enquanto a câmera mostra de leve suas curvas. Apesar da masculinidade se apresentar desconstruída dentro do comercial, ela precisa ser reafirmada em contraste ao gênero oposto; ademais, a figura feminina é mais uma vez sensualizada na cena para atestar a heterossexualidade do protagonista, associando, a masculinidade a ela. 


\section{Considerações Finais}

A sociedade pós-moderna é marcada pelas identidades fluídas e seu caráter constantemente inacabado é fruto de uma construção cultural e simbólica em que os indivíduos buscam referências identitárias com que se identifiquem para confirmar e constituir a própria. Nesse âmbito, assim como outras produções midiáticas, a publicidade ultrapassa os limites unicamente comerciais e reproduz discursos que compõem o sistema simbólico de representação social, ao mesmo tempo em que projeta identidades culturais e hegemônicas a serem seguidas.

A construção social e visual da masculinidade hegemônica é discursivamente influenciada por produções publicitárias, sobretudo quando estão associadas a uma figura aclamada e uma personalidade midiática representada como um modelo social a serseguido. Nesta pesquisa, foram comparadas duas peças publicitárias protagonizadas pelo ator Malvino Salvador em anos diferentes, porém muito próximos, e com abordagens distintas de masculinidade, tendo em vista a fragilidade que acompanha a mesma e a sua necessidade de reafirmação, sobretudo após a consolidação da sociedade líquido-moderna e o afloramento do movimento feminista, como uma oposição ao domínio masculino e como um movimento contra-hegemônico. Portanto, as diferentes atribuições representativas direcionadas ao ator Malvino Salvador, após a análise do seu conteúdo, e a categorização dos elementos ligados à identidade masculina, em ambas as peças, indicam que diferentes modelos de masculinidade coexistem numa mesma época. Mais além, as ambiguidades e disparidades entre estas não impossibilitam que uma mesma figura midiática as represente. Se representações que celebram a virilidade em uma perspectiva machista que, para enaltecê-la, retrata mulheres como seres passivos e dominados ainda estão em vigência, como vimos ao analisar a produção publicitária destinada à marca Old Spice, também é verdade que o questionamento a este modelo é crescente e reverbera principalmente nos espaços virtuais, dando cada vez mais espaço a outras representações do "modo de ser homem" na mídia.

\section{Referências Bibliográficas}

BADINTER, Elisabeth. (1993). XY: sobre a Identidade Masculina. Rio de Janeiro: Nova Fronteira.

BARDIN, Laurence. (2006). Análise de conteúdo. Lisboa: Edições 70.

BAUMAN, Zygmunt. (2005). Identidade: Entrevista a Benedetto Vecchi. Rio de Janeiro: Jorge Zahar Ed.

BAUMAN, Zygmunt. (2001). Modernidade Líquida. 1 a edição. Rio de Janeiro: Jorge Zahar Ed. 
DAMATTA, Roberto. (2010). “Tem pente aí?: reflexões sobre a identidade masculina”. Revista Enfoques, n.1, 9: p.134-151, agosto.

DUARTE, Jorge; BARROS, Antônio (Eds.). (2010). Métodos e Técnicas de pesquisa em Comunicação. 2 a edição. São Paulo: Atlas.

FARINA, Modesto; PEREZ, Clotilde; Bastos, Dorinho. (2011). Psicodinâmica das cores em comunicação. 6 a edição. São Paulo: Blucher.

HALL, Stuart. (2011) “Quem precisa de identidade?” In: SILVA, Tomaz Tadeu (ed.). Identidade e diferença: A Perspectiva dos Estudos Culturais, 7 a edição. Petrópolis: Vozes. p. 103-133.

KELLNER, Douglas. (2001). A cultura da mídia: estudos culturais, identidade e política entre o moderno e o pós-moderno. Bauru: Edusc.

MALTA, Renata Barreto. (2013). A comunicação no mercado do imaterial: Tensões e distensões da produção simbólica em uma era pós-material. Tese (Doutorado em Comunicação Social) - Universidade Metodista de São Paulo, São Bernardo do Campo.

MARCONDES FILHO, Ciro. (2009). “Comunicação”. In: MARCONDES FILHO, Ciro. (Ed.). Dicionário da comunicação. São Paulo: Paulus.

MERTON, Robert; LAZARSFELD, Paul. (1990). "Comunicação de Massa, Gosto Popular e a Organização da Ação Social”. In: LIMA, Luiz Costa (Ed.) Teoria da Cultura de Massa. Rio de Janeiro: Paz e Terra.

MORAES, Roque. (1999). “Análise de conteúdo”. Revista Educação, n. 37, 22: p.7-32.

SILVA, Tomaz Tadeu da. (2011) "A Produção Social da Identidade e da Diferença". In: SILVA, Tomaz Tadeu da (Ed.). Identidade e Diferença: a Perspectiva dos Estudos Culturais. 7 a edição. Petrópolis: Vozes.

WILLIAMS, Raymond. (2011). "Publicidade: O Sistema Mágico”. In: Cultura e Materialismo. São Paulo: Editora Unesp.

WOODWARD, Kathryn. (2011) "Identidade e Diferença: Uma Introdução Teórica e Conceitual”. In: SILVA, Tomaz. Tadeu. (Ed.). Identidade e Diferença: A perspectiva dos Estudos Culturais. 7 a edição. Petrópolis: Vozes.

Recebido: 27.07.2017

Aceito: 30.06 .2018 